\title{
Erratum to: Testing and fracture mechanics analysis of strength effects on the fatigue behavior of HFMI-treated welds
}

\author{
Rakesh Ranjan $^{1} \cdot$ Kasra Ghahremani $^{1} \cdot$ Scott Walbridge $^{1} \cdot$ Ayhan Ince $^{2}$
}

Published online: 28 June 2016

(C) International Institute of Welding 2016

\section{Erratum to: Weld World}

DOI 10.1007/s40194-016-0354-4

In the original publication of the article unfortunately in Figures 4 and 14 the reference citation [22] is wrong, it should read [13]. The correct Figure 4 and 14 are displayed now.

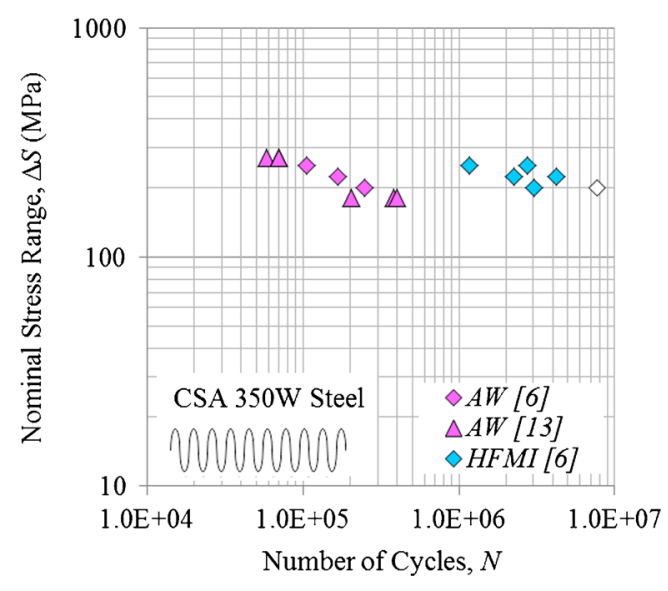

Fig. 4 CA results for CSA $350 \mathrm{~W}$ steel from $[6,13]$

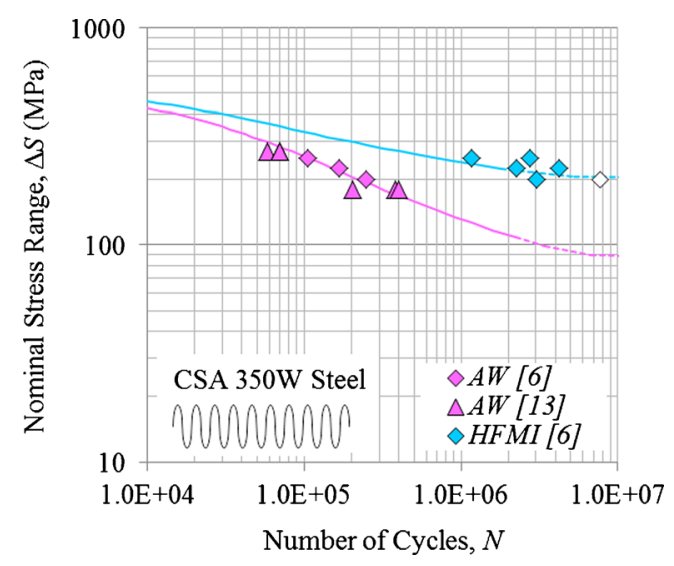

Fig. 14 Fracture mechanics analysis result for CSA 350W steel (CA loading) 